\title{
Safety and interim survival data after intracranial administration of M032, a genetically engineered oncolytic HSV-1 expressing IL-12, in pet dogs with sporadic gliomas
}

\author{
Nidal B. Omar, MD, ${ }^{1}$ R. Timothy Bentley, BVSc, ${ }^{4}$ David K. Crossman, PhD, ${ }^{2}$ \\ Jeremy B. Foote, DVM, PhD, ${ }^{3}$ Jennifer W. Koehler, DVM, PhD, James M. Markert, MD, MPH, ${ }^{1}$ \\ Simon R. Platt, BVM\&S, ${ }^{5}$ Daniel R. Rissi, DVM, MS, PhD, ${ }^{5}$ Andy Shores, DVM, MS, PhD, ${ }^{6}$ \\ Donald Sorjonen, DVM, MS, ${ }^{7}$ Amy B. Yanke, DVM, MS, ${ }^{7}$ G. Yancey Gillespie, PhD, ${ }^{1}$ and \\ Melissa R. Chambers, DVM, MD1 \\ Departments of ${ }^{1}$ Neurosurgery, ${ }^{2}$ Genetics, and ${ }^{3}$ Microbiology, The University of Alabama at Birmingham, Alabama; ${ }^{4}$ Purdue

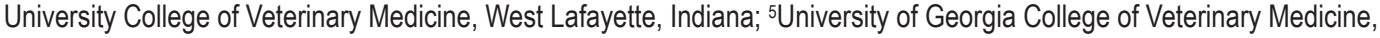 \\ Athens, Georgia; ${ }^{6}$ Mississippi State University College of Veterinary Medicine, Mississippi State, Mississippi; and ${ }^{7}$ Auburn \\ University College of Veterinary Medicine, Auburn, Alabama
}

\begin{abstract}
OBJECTIVE The diagnosis of glioma remains disheartening in the clinical realm. While a multitude of studies and trials have shown promise, improvements in overall survival have been disappointing. Modeling these tumors in the laboratory setting has become increasingly challenging, given their complex in situ behavior and interactions for therapeutic evasion. Dogs, particularly brachycephalic breeds, are known to spontaneously develop gliomas that resemble human gliomas both clinically and pathophysiologically, making canines with sporadic tumors promising candidates for study. Typically, survival among these dogs is approximately 2 months with palliation alone.
\end{abstract}

METHODS The authors have completed the first stage of a unique phase I dose-escalating canine clinical trial in which the safety and tolerability of M032, a nonneurovirulent oncolytic herpes simplex virus-1 vector genetically engineered to express interleukin-12, are being studied in pet dogs with gliomas undergoing maximum safe tumor resection and inoculation of the cavity with the viral infusate.

RESULTS Twenty-five canine patients were enrolled between January 2018 and August 2020. One patient was electively withdrawn from the trial by its owner, and 3 did not receive the virus. For the 21 dogs that remained, 13 had high-grade gliomas, 5 had low-grade gliomas, and 3 were undetermined. According to histopathological analysis, $62 \%$ of the tumors were oligodendrogliomas. At the time of this report, the median overall survival from the date of treatment was 151 days ( \pm 78 days). No significant adverse events attributable to M032 or dose-limiting toxicities have been observed to date.

CONCLUSIONS In this largest study of oncolytic viral therapy for canine brain tumors to date, treatment with M032 did not cause harm and the combination of surgery and oncolytic viral therapy may have contributed to prolonged survival in pet dogs with spontaneous gliomas. Forthcoming in-depth radiographic, immunohistochemical, and genetic analyses will afford a more advanced understanding of how this treatment impacts these tumors and the immune system. Our goal is to utilize these findings bitranslationally to inform human studies and refine therapies that will improve outcomes in both humans and pet dogs with gliomas.

https://thejns.org/doi/abs/10.3171/2020.11.FOCUS20844

KEYWORDS One Health Consortium; glioma; oncolytic virus; immunotherapy; canine; bitranslational

$\mathrm{G}$ LIOMA is a harrowing diagnosis. While the expanded implementations of whole-genome sequencing and targeted therapies have afforded above-average outcomes to some patients, the overall prognosis for the most malignant of these tumors remains poor, with a median survival of approximately 17 months from diagnosis. ${ }^{1}$ An unprecedentedly vast and multifaceted field of research has been dedicated to achieving improved survival and cure for this heterogeneous disease entity. Decades of basic science and translational and clinical research have

ABBREVIATIONS HSV-1 = herpes simplex virus-1; IDO = indoleamine dioxygenase; IL-12 = interleukin-12; oHSV = oncolytic herpes simplex virus; pfu = plaque-forming units.

SUBMITTED September 29, 2020. ACCEPTED November 12, 2020.

INCLUDE WHEN CITING DOI: 10.3171/2020.11.FOCUS20844. 
led to multiple preclinical and clinical trials investigating experimental treatments. ${ }^{2-4}$

Oncolytic viral vectors comprise a major frontier in the pursuit of effective therapies for gliomas. ${ }^{5}$ The ability to engineer viruses to tame their neurovirulence while enhancing their ability to infect and kill tumor cells has proven a major asset to their study. Additionally, the ability to recruit and potentiate innate immune responses (which have often been suppressed by the tumors) through cross-epitope spreading provides an avenue of intersection with immunotherapeutic studies.

In the search for an appropriate preclinical model to inform human glioma clinical trials, it can be difficult to extrapolate data from immunologically nude organisms and those with induced pathology. While these laboratory-based studies have yielded essential data, the current understanding of the complex in vivo behavior of these tumors and their far-reaching systemic consequences pose unique challenges to their study. Notably, some breeds of dogs are known to harbor spontaneously and sporadically occurring gliomas that resemble those of their human counterparts-clinically, radiographically, immunohistologically, and genetically. They also follow similar treatment and outcome patterns, albeit on a different scale. ${ }^{6}$

The "One Health" approach to medicine is a global public health paradigm with an integrative and collaborative approach to human and animal health. ${ }^{7,8}$ The One Health Consortium was created to evaluate treatment of innate diseases in pets and correlate the resulting data with data from human studies for synergistic benefit to both. Harnessing the similarities between human and canine gliomas provides an avenue of great potential and exemplifies the One Health approach to medicine.

The authors have previously published background work and the design of an ongoing phase I clinical trial, known as "CANINE," studying the use of a genetically engineered herpesvirus with or without an immune checkpoint inhibitor in pet dogs with sporadic gliomas. ${ }^{9} \mathrm{M} 032$ is an oncolytic herpes simplex virus-1 (HSV-1) vector with deletion of its neurovirulent $\gamma 34.5$ subunit, further engineered to express human interleukin-12 (IL-12). ${ }^{10}$ Human IL-12 has previously been shown in veterinary studies to induce a systemic T-cell response in dogs. ${ }^{11} \mathrm{HSV}-1$ is not a pathogenic alphaherpesvirus in dogs and therefore would not be expected to cause an active infection in healthy central nervous system or systemic tissues. A previous study of a nonneurovirulent HSV-1 strain injected into the brains of healthy dogs indicated permissiveness to latent infection, with evidence of latent viral DNA as distant as the contralateral hemisphere. ${ }^{12}$ In unpublished preclinical work by Gillespie et al., the cytotoxicity of M032 to canine glioma cells in vitro was equivalent to that of mouse and human glioma cell lines (plaque-forming units [pfu]/50\% lethal dose $[\mathrm{LD} 50]=6.6$ ). The M032 virus is concurrently being studied in a human clinical trial for recurrent glioblastoma. ${ }^{13}$ Thus, in a novel fashion, head-to-head comparison of data from these trials should afford combined insight into the tumoral and systemic effects of treatment and certain nuances that the human study alone may not feasibly afford.

The CANINE trial has recently completed enrolling patients in its first stage, investigating the safety and tolerability of M032 viral inoculation alone following maximum safe tumor resection. The second stage of the trial will include intracranial M032 administration with addition of the orally administered systemic immune checkpoint inhibitor indoximod, which targets the indoleamine dioxygenase (IDO)-mediated immune evasion pathway that human gliomas and many canine malignancies are known to exploit..$^{14,15}$ Herein, the authors present a brief interim report on the clinical findings, safety, and survival data to date in the stage I cohort receiving M032 alone.

\section{Methods}

The Institutional Animal Care and Use Committee (IACUC) approval to conduct this trial was obtained from The University of Alabama at Birmingham (IACUC-21115) as well as from respective IACUCs at participating colleges of veterinary medicine. Beginning in January 2018, canine patients with presumptive diagnoses of glioma based on history, clinical examination, and imaging were screened and enrolled with informed consent from pet owners. Dogs were required to be greater than 6 months of age at enrollment and otherwise healthy enough to have had a life expectancy of greater than 6 months barring their intracranial tumors. Tumors that would require ventricular, basal ganglia, brainstem, or posterior fossa inoculation were excluded.

Steroid administration was allowable if the dose did not increase within 2 weeks of surgery and the total dose did not exceed a dexamethasone equivalent of $2 \mathrm{mg} / \mathrm{kg}$ per day at the time of surgery. All patients that were not already therapeutically treated with an antiepileptic drug were started on levetiracetam at a daily dose of at least $500 \mathrm{mg}$ and required to continue the medication for at least 6 weeks unless an adverse reaction was encountered. Treatment in all cases was scheduled within 2 weeks of enrollment.

On the first day of treatment, each dog was placed under general anesthesia and underwent a craniotomy for maximum safe resection of their glial tumor by the participating veterinary neurosurgeon. Following either gross-total or subtotal resection, a catheter was implanted within the resection cavity, with the proximal end fixed to an accessible reservoir in the subcutaneous space. The catheter was confirmed to be in an appropriate position via postoperative $\mathrm{CT}$ imaging.

After a period of postoperative recovery and monitoring, and upon histological confirmation of diagnosis within 48 hours of surgery, intracranial inoculation with the M032 virus was performed in each patient via a single 1 -mL infusion $(0.5 \mathrm{~mL}$ of viral solution and $0.5 \mathrm{~mL}$ of sterile vehicle) through the subcutaneous reservoir. The viral dose was determined via the previously published dose escalation scheme in subsequent cohorts of dogs (Tables 1 and 2)..$^{9}$ A protocolized schedule of inpatient and subsequent outpatient clinical, radiographic, and laboratory surveillance for adverse effects and dose-limiting toxicities has been previously described through a period of 12 months following treatment (Table 3). ${ }^{9}$

Histological diagnoses of oligodendroglioma, astrocy- 
TABLE 1. Dose escalation decision criteria

\begin{tabular}{cc}
$\begin{array}{c}\text { Number of patients with dose-limiting toxicity } \\
\text { (DLT) at given dose level }\end{array}$ & Escalation decision rule \\
\hline 0 out of 3 & Enter 3 patients at the next dose level \\
\hline$>=2$ & $\begin{array}{c}\text { Dose escalation will be stopped. This dose level will be declared the maximally tolerated dose (high- } \\
\text { est dose administered). } 3 \text { additional patients will be entered at the next lowest dose level if only } 3 \\
\text { patients were treated previously at that dose }\end{array}$ \\
\hline $\begin{array}{c}\text { Enter up to } 3 \text { more patients at this dose level } \\
\text { out of } 3\end{array}$ & $\begin{array}{c}\text {-If } 0 \text { out of these } 3 \text { patients experience DLT, proceed to the next dose level } \\
\text { maximally administered dose. } 3 \text { additional patients will be entered at the next lowest dose level if } \\
\end{array}$ \\
& only 3 patients were treated previously at that dose \\
\hline$</=1$ out of 6 at highest dose level & This is generally the recommended phase 2 dose. At least 6 patients must be entered at the recom- \\
below the maximally administered dose & mended phase 2 dose
\end{tabular}

DLT = dose-limiting toxicity.

Reprinted with permission from Chambers MR, Bentley RT, Crossman DK, Foote JB, Koehler JW, Markert JM, Omar NB, Platt SR, Self DM, Shores A, Sorjonen DC, Waters AM, Yanke AB and Gillespie GY (2020). The One Health Consortium: design of a phase I clinical trial to evaluate M032, a genetically engineered HSV-1 expressing IL-12, in combination with a checkpoint inhibitor in canine patients with sporadic high grade gliomas. Front. Surg. 7:59. Copyright 2020, the Authors. CC BY 4.0 (https://creativecommons.org/licenses/by/4.0/).

toma, or undefined glioma and assignment of low or high grade were made by the participating veterinary pathologists and based on the NCI Comparative Brain Tumor Consortium (CBTC) Pathology Board criteria. ${ }^{16}$

Basic descriptive statistics including mean and standard deviation were calculated using the Microsoft Excel (2007) functions "AVERAGE" and "STDEV" respectively. A Kaplan-Meier survival plot and median survival values were generated using the SigmaPlot software.

\section{Results}

Between January 2018 and August 2020, 25 dogs were enrolled in the trial. Table 4 shows canine characteristics and basic information about the tumors.

Two dogs (nos. 004 and 005) had undergone previous treatment of their tumors with surgically implanted temozolomide/gadolinium-impregnated beads approximately 8 and 5 months prior, respectively-both with imagingconfirmed progression. After treatment, 1 dog (no. 007) left the study to undergo alternate therapies and 3 dogs (nos. 015, 022, and 024) underwent tumor resection with catheter implantation but died of postoperative aspiration pneumonia prior to intracranial inoculation with the M032 virus. Of the remaining 21 canines, 16 were male and 5 were female. The mean $( \pm \mathrm{SD})$ age at treatment was $8 \pm$ 2 years.

In the remaining 21 cases, 13 tumors were located in the right hemisphere and 8 were located in the left. Maximum safe resection was performed in all cases at the discretion of the veterinary neurosurgeon. Tumor morphology based on assessment of H\&E-stained tissue specimens was consistent with oligodendroglioma in 13 cases (62\%) (Fig. 1), astrocytoma in 5 cases (23\%) (Fig. 2), glioblastoma in 1 case $(5 \%)$, and undefined glioma (low grade, with astrocytic features) in 1 case (5\%), and was undetermined (imaging and intraoperative features clearly representing glioma but tumor histology indeterminate) in 1 case $(5 \%)$. Among the oligodendrogliomas, 9 were high grade, 3 were low grade, and 1 lacked sufficient tissue for determination. Among the astrocytomas, 3 were high grade, 1 was low grade, and 1 was undetermined. Intratumoral expression of Ki-67 in 11 of the tumors evaluated to date was clearly elevated for both high-grade oligodendroglio-

TABLE 2. Dose-escalation schedule for canine patients

\begin{tabular}{ccc}
\hline & \multicolumn{2}{c}{ Dose of MO32* plaque forming units (pfu) } \\
\cline { 2 - 3 } Dose level & Stage 1 & Stage 2 \\
\hline Level 1 & $1 \times 10^{6} \mathrm{pfu}$ & \\
\hline Level 2 & $1 \times 10^{7} \mathrm{pfu}$ & $1 \times 10^{8} \mathrm{pfu}+1,200 \mathrm{mg} / \mathrm{M}^{2} \mathrm{Indoximod}$ \\
\hline Level 3 & $1 \times 10^{8} \mathrm{pfu}$ & \\
\hline Level 4 & $1 \times 10^{9} \mathrm{pfu}$ & \\
\hline
\end{tabular}

Modified with permission from Chambers MR, Bentley RT, Crossman DK, Foote JB, Koehler JW, Markert JM, Omar NB, Platt SR, Self DM, Shores A, Sorjonen

DC, Waters AM, Yanke AB and Gillespie GY (2020). The One Health Consortium: design of a phase I clinical trial to evaluate M032, a genetically engineered HSV-1 expressing IL-12, in combination with a checkpoint inhibitor in canine patients with sporadic high grade gliomas. Front. Surg. 7:59. Copyright 2020, the Authors. CC BY 4.0 (https://creativecommons.org/licenses/by/4.0/).

${ }^{*}$ Doses are stated as exact doses in plaque forming units rather than as a percentage. 
TABLE 3. Study schedule

\begin{tabular}{|c|c|c|c|c|c|c|c|c|c|c|c|}
\hline & $\begin{array}{l}\text { Prestudy (within } 2 \\
\text { weeks prior to MO32 } \\
\text { administration) }\end{array}$ & $\begin{array}{c}\text { Day } \\
0\end{array}$ & $\begin{array}{c}\text { Day } \\
1\end{array}$ & $\begin{array}{c}\text { Day } \\
2\end{array}$ & $\begin{array}{c}\text { Day } \\
3\end{array}$ & $\begin{array}{l}\text { Day } 14 \\
(+/-4 \\
\text { days })\end{array}$ & $\begin{array}{c}\text { Day } 28 \\
(+/-4 \\
\text { days })\end{array}$ & $\begin{array}{c}\text { Month } 3 \\
(+/-12 \\
\text { days })\end{array}$ & $\begin{array}{c}\text { Month } 6 \\
(+/ 212 \\
\text { days })\end{array}$ & $\begin{array}{c}\text { Month } 9 \\
(+/-12 \\
\text { days })\end{array}$ & $\begin{array}{l}\text { Month } \\
12(+/- \\
12 \text { days })\end{array}$ \\
\hline Informed consent & $x$ & & & & & & & & & & \\
\hline Inclusion/exclusion criteria & $x$ & & & & & & & & & & \\
\hline Signalment & $x$ & & & & & & & & & & \\
\hline Pregnancy test (serum) & $x$ & & & & & & & & & & \\
\hline Medical history & $x$ & & & & & & & & & & \\
\hline Concurrent meds & $x$ & $x$ & $x$ & $x$ & $x$ & $x$ & $x$ & $x$ & $x$ & $x$ & $x$ \\
\hline $\begin{array}{l}\text { Complete physical exam (with wound as- } \\
\text { sessment Days 1-14) }\end{array}$ & $x$ & & $x$ & $x$ & $x$ & $x$ & $x$ & $x$ & $x$ & $x$ & $x$ \\
\hline Vital signs & $x$ & $x$ & $x$ & $x$ & $x$ & $x$ & $x$ & $x$ & $x$ & $x$ & $x$ \\
\hline CBC, c diff, platelets & $x$ & & & $x$ & & $x$ & $x$ & $x$ & $x$ & $x$ & $x$ \\
\hline Serum chemistries, PT/PTT, INR & $x$ & & & $x$ & & $x$ & $x$ & $x$ & $x$ & $x$ & $x$ \\
\hline Kynurenine levels (serum) & $x$ & & & $x$ & & $x$ & $x$ & $x$ & $x$ & $x$ & $x$ \\
\hline EKG & $x$ & & & & & & & & & & \\
\hline CXR (AP and lateral) & $x$ & & & & & & & & & & \\
\hline Urinalysis with micro & $x$ & & & & & & & & & & \\
\hline Adverse event evaluation & & $x$ & $x$ & $x$ & $x$ & $x$ & $x$ & $x$ & $x$ & $x$ & $x$ \\
\hline MRI & $x$ & & & & & & $x$ & $x$ & $x$ & & \\
\hline Neurologic exam & $x$ & $x$ & $x$ & $x$ & $x$ & $x$ & $x$ & $x$ & $x$ & $x$ & $x$ \\
\hline HSV Ab titer & $x$ & & & & & $x$ & $x$ & $x$ & $x$ & $x$ & $x$ \\
\hline $\begin{array}{l}\text { HSV detection (saliva, conjunctival secre- } \\
\text { tions, and/or blood) }\end{array}$ & $x$ & & & $x$ & $x^{*}$ & $x$ & $x$ & $x$ & $x$ & $x$ & $x$ \\
\hline IL-12 detection (serum) & $x$ & & & $x$ & $x$ & $x$ & $x$ & $x$ & $x$ & $x$ & $x$ \\
\hline MO32 administration & & $x$ & & & & & & & & & \\
\hline Blood for LTA, Elispot & $x$ & & & $x$ & $x$ & $x$ & $x$ & $x$ & $x$ & $x$ & $x$ \\
\hline Blood to be stored for future immune studies & $x$ & $x$ & & $x$ & $x$ & $x$ & $x$ & $x$ & $x$ & $x$ & $x$ \\
\hline Head CT & & $x$ & & & & & & & & & \\
\hline Surgery, catheter placement & & $x$ & & & & & & & & & \\
\hline $\begin{array}{l}\text { Levetiracetam (prophylactic AED) daily } \times 6 \\
\text { weeks beginning prior to Day } 0^{* *}\end{array}$ & & & & $x$ & & & & & & & \\
\hline $\begin{array}{l}\text { Indoximod administration, daily } \times 28 \text { days } \\
\text { beginning at Day } 0^{* * *}\end{array}$ & & & & & $x$ & & & & & & \\
\hline
\end{tabular}

$\mathrm{Ab}=$ antibody; $\mathrm{AED}=$ antiepileptic drug; $\mathrm{AP}=$ anterior-posterior; $\mathrm{CBC}=$ complete blood count; $C X R=$ chest $\mathrm{x}$-ray; INR = international normalized ratio; $\mathrm{LTA}=$ light transmission aggregometry; PT = prothrombin time; $\mathrm{PTT}=$ partial thromboplastin time.

Modified with permission from Chambers MR, Bentley RT, Crossman DK, Foote JB, Koehler JW, Markert JM, Omar NB, Platt SR, Self DM, Shores A, Sorjonen DC, Waters AM, Yanke AB and Gillespie GY (2020). The One Health Consortium: design of a phase I clinical trial to evaluate M032, a genetically engineered HSV-1 expressing IL-12, in combination with a checkpoint inhibitor in canine patients with sporadic high grade gliomas. Front. Surg. 7:59. Copyright 2020, the Authors. CC BY 4.0 (https://creativecommons.org/licenses/by/4.0/).

* Blood only.

${ }^{* *} \mathrm{AED}$ discontinued prior to 6 weeks if adverse reaction. After 6 weeks, continuation is at the discretion of attending veterinarian.

${ }^{* * *}$ Stage 2 of trial.

mas and astrocytomas relative to respective low-grade tumors, although the analysis was not sufficiently powered to reach statistical significance (Fig. 3).

As of this writing, of the 21 dogs remaining in the trial, 15 dogs were deceased and 6 were still alive, and the median overall survival from the date of treatment was $151 \pm$ 78 days. For the deceased dogs $(n=15)$, the mean survival was $134 \pm 128$ days, and for the dogs meeting or exceeding the designated provisional surveillance period of 12 months \pm 12 days $(\mathrm{n}=3)$, the mean survival was $370 \pm 8$ days. When stratified by tumor grade, the mean survival among dogs with definitively high-grade gliomas $(n=13)$ was $108 \pm 107$ days, and among low-grade gliomas ( $\mathrm{n}=$ 5) it was $211 \pm 151$ days. Current survival data trends are illustrated in Fig. 4.

No significant adverse events directly referable to treatment with M032 have been identified at any dose level. Three dogs (nos. 001, 008, and 009) required repositioning of their inoculation catheters based on immediate postoperative CT imaging. One dog (no. 018) developed transient 
TABLE 4. Interim data on canine characteristics, viral dosing, tumor pathology, and survival after administration of M032

\begin{tabular}{|c|c|c|c|c|c|c|c|c|c|c|}
\hline $\begin{array}{l}\text { ID } \\
\text { No. }\end{array}$ & $\begin{array}{c}\text { Age at } \\
\text { Treatment } \\
\text { (yrs) }\end{array}$ & $\begin{array}{l}\text { Weight at } \\
\text { Treatment } \\
(\mathrm{kg})\end{array}$ & $\begin{array}{l}\text { Sex-Neuter, } \\
\text { Spay, or } \\
\text { Intact }\end{array}$ & Breed & $\begin{array}{l}\text { Tumor } \\
\text { Location }\end{array}$ & $\begin{array}{c}\text { Prior } \\
\text { Treatment }\end{array}$ & $\begin{array}{l}\text { M032 } \\
\text { Dose } \\
\text { (pfu) }\end{array}$ & $\begin{array}{c}\text { Tumor } \\
\text { Pathology }\end{array}$ & $\begin{array}{l}\text { Tumor } \\
\text { Grade }\end{array}$ & $\begin{array}{l}\text { Posttreatment } \\
\text { Survival (days) }\end{array}$ \\
\hline 001 & 6 & 14.1 & $M-N$ & $\begin{array}{l}\text { English } \\
\text { Bulldog }\end{array}$ & $\begin{array}{l}\text { Lt frontal/ } \\
\text { parietal lobe }\end{array}$ & No & $1 \mathrm{E}+06$ & Oligodendroglioma & Low & 108 \\
\hline 002 & 10 & 24.1 & $M-N$ & Boxer & Rt frontal lobe & No & $1 \mathrm{E}+06$ & Oligodendroglioma & High & 372 \\
\hline 003 & 7 & 23.0 & $\mathrm{M}-\mathrm{N}$ & $\begin{array}{l}\text { English } \\
\text { Bulldog }\end{array}$ & $\begin{array}{l}\text { Lt parietal/ } \\
\text { occipital lobe }\end{array}$ & No & $1 \mathrm{E}+06$ & Oligodendroglioma & High & 232 \\
\hline 004 & 9 & 7.03 & M-N & $\begin{array}{l}\text { Yorkshire } \\
\text { Terrier }\end{array}$ & Rt frontal lobe & Yes & $1 \mathrm{E}+07$ & Astrocytoma & Low & 188 \\
\hline 005 & 7 & 53.0 & $\mathrm{M}-\mathrm{N}$ & $\begin{array}{l}\text { Mixed } \\
\text { breed }\end{array}$ & Lt piriform lobe & Yes & $1 \mathrm{E}+07$ & Oligodendroglioma & High & 151 \\
\hline 006 & 6 & 10.8 & $M-N$ & $\begin{array}{l}\text { Boston } \\
\text { Terrier }\end{array}$ & Rt forebrain & No & $1 \mathrm{E}+07$ & Astrocytoma & Undetermined & 415 \\
\hline 007 & 7 & 12.7 & $\mathrm{M}-\mathrm{N}$ & $\begin{array}{l}\text { Mixed } \\
\text { breed }\end{array}$ & $\begin{array}{l}\text { Rt rostral } \\
\text { fossa }\end{array}$ & No & $1 \mathrm{E}+08$ & Oligodendroglioma & Undetermined & $\begin{array}{l}\text { Left study to pursue } \\
\text { alternate treatment }\end{array}$ \\
\hline 008 & 6 & 55.2 & F-S & $\begin{array}{l}\text { German } \\
\text { Shepherd }\end{array}$ & Rt frontal lobe & No & $1 \mathrm{E}+08$ & Oligodendroglioma & High & 41 \\
\hline 009 & 11 & 8.6 & F-S & $\begin{array}{l}\text { Boston } \\
\text { Terrier }\end{array}$ & $\begin{array}{l}\text { Rt frontal/ } \\
\text { parietal lobe }\end{array}$ & No & $1 \mathrm{E}+08$ & Astrocytoma & High & 11 \\
\hline 010 & 7 & 34.4 & $M-N$ & $\begin{array}{l}\text { American } \\
\text { Bulldog }\end{array}$ & $\begin{array}{l}\text { Rt temporal } \\
\text { lobe }\end{array}$ & No & $1 \mathrm{E}+09$ & Oligodendroglioma & High & 43 \\
\hline 011 & 4 & 52.0 & M-N & $\begin{array}{l}\text { Great } \\
\text { Dane }\end{array}$ & Lt forebrain & No & $1 \mathrm{E}+09$ & Oligodendroglioma & High & 219 \\
\hline 012 & 11.5 & 11.4 & $\mathrm{M}-\mathrm{N}$ & $\begin{array}{l}\text { Boston } \\
\text { Terrier }\end{array}$ & Lt frontal lobe & No & $1 \mathrm{E}+09$ & Oligodendroglioma & Undetermined & $378^{*}$ \\
\hline 013 & 8 & 39.6 & F-S & $\begin{array}{l}\text { Mixed } \\
\text { breed }\end{array}$ & $\begin{array}{l}\text { Rt temporal } \\
\text { lobe }\end{array}$ & No & $1 \mathrm{E}+09$ & Oligodendroglioma & High & 43 \\
\hline 014 & 8 & 11.6 & $\mathrm{M}-\mathrm{N}$ & $\begin{array}{l}\text { Boston } \\
\text { Terrier }\end{array}$ & Lt frontal lobe & No & $1 \mathrm{E}+09$ & Oligodendroglioma & Low & $369^{*}$ \\
\hline 015 & 14.5 & 41.0 & $\mathrm{M}-\mathrm{N}$ & Boxer & $\begin{array}{l}\text { Rt temporal } \\
\text { lobe }\end{array}$ & No & NA & Oligodendroglioma & Low & $\begin{array}{l}\text { Died of pneumonia } \\
\text { prior to inoculation }\end{array}$ \\
\hline 016 & 10 & 24.1 & F-S & $\begin{array}{l}\text { Border } \\
\text { Collie }\end{array}$ & Rt forebrain & No & $1 \mathrm{E}+09$ & $\begin{array}{c}\text { Undefined with } \\
\text { astrocytic features }\end{array}$ & Low & $362^{*}$ \\
\hline 017 & 11 & 8.47 & $\mathrm{M}-\mathrm{N}$ & $\begin{array}{l}\text { Boston } \\
\text { Terrier }\end{array}$ & $\begin{array}{l}\text { Rt temporal } \\
\text { lobe }\end{array}$ & No & $1 \mathrm{E}+09$ & Oligodendroglioma & Low & 28 \\
\hline 018 & 9.5 & 11.6 & $\mathrm{M}-\mathrm{N}$ & $\begin{array}{l}\text { French } \\
\text { Bulldog }\end{array}$ & Lt parietal lobe & No & $1 \mathrm{E}+09$ & Oligodendroglioma & High & 70 \\
\hline 019 & 9 & 5.0 & M-N & $\begin{array}{l}\text { Yorkshire } \\
\text { Terrier }\end{array}$ & $\begin{array}{l}\text { Rt temporal } \\
\text { lobe }\end{array}$ & No & $1 \mathrm{E}+09$ & Glioblastoma & High & 55 \\
\hline 020 & 5 & 26.0 & $\mathrm{M}-\mathrm{N}$ & $\begin{array}{l}\text { Mixed } \\
\text { breed }\end{array}$ & $\begin{array}{l}\text { Rt temporal } \\
\text { lobe }\end{array}$ & No & $1 \mathrm{E}+09$ & Oligodendroglioma & High & 28 \\
\hline 021 & 5 & 28.6 & $\mathrm{M}-\mathrm{N}$ & $\begin{array}{l}\text { Golden } \\
\text { Retriever }\end{array}$ & $\begin{array}{l}\text { Rt occipital } \\
\text { lobe }\end{array}$ & No & $1 \mathrm{E}+09$ & Astrocytoma & High & $103^{*}$ \\
\hline 022 & 6.5 & 34 & $\mathrm{M}-\mathrm{N}$ & Boxer & $\begin{array}{l}\text { Lt temporal } \\
\text { lobe }\end{array}$ & No & NA & $\begin{array}{l}\text { Granulomatous me- } \\
\text { ningoencephalitis }\end{array}$ & NA & $\begin{array}{l}\text { Died of pneumonia } \\
\text { prior to inoculation }\end{array}$ \\
\hline 023 & 7 & 29.1 & F-S & $\begin{array}{l}\text { Mixed } \\
\text { breed }\end{array}$ & $\begin{array}{l}\text { Rt temporal } \\
\text { lobe }\end{array}$ & No & $1 \mathrm{E}+09$ & Undetermined & Undetermined & $39^{*}$ \\
\hline 024 & 7.5 & 33.1 & M-I & Boxer & Lt frontal lobe & No & NA & Glioblastoma & High & $\begin{array}{l}\text { Died of pneumonia } \\
\text { prior to inoculation }\end{array}$ \\
\hline 025 & 6.5 & 37.2 & $M-I$ & $\begin{array}{l}\text { Cane } \\
\text { Corso }\end{array}$ & $\begin{array}{l}\text { Lt frontal/ } \\
\text { parietal lobe }\end{array}$ & No & $1 \mathrm{E}+09$ & Astrocytoma & High & $33^{*}$ \\
\hline
\end{tabular}

I = intact; $\mathrm{N}=$ neutered; $\mathrm{NA}=$ not applicable; $\mathrm{S}=$ spayed.

* Canines still living. 


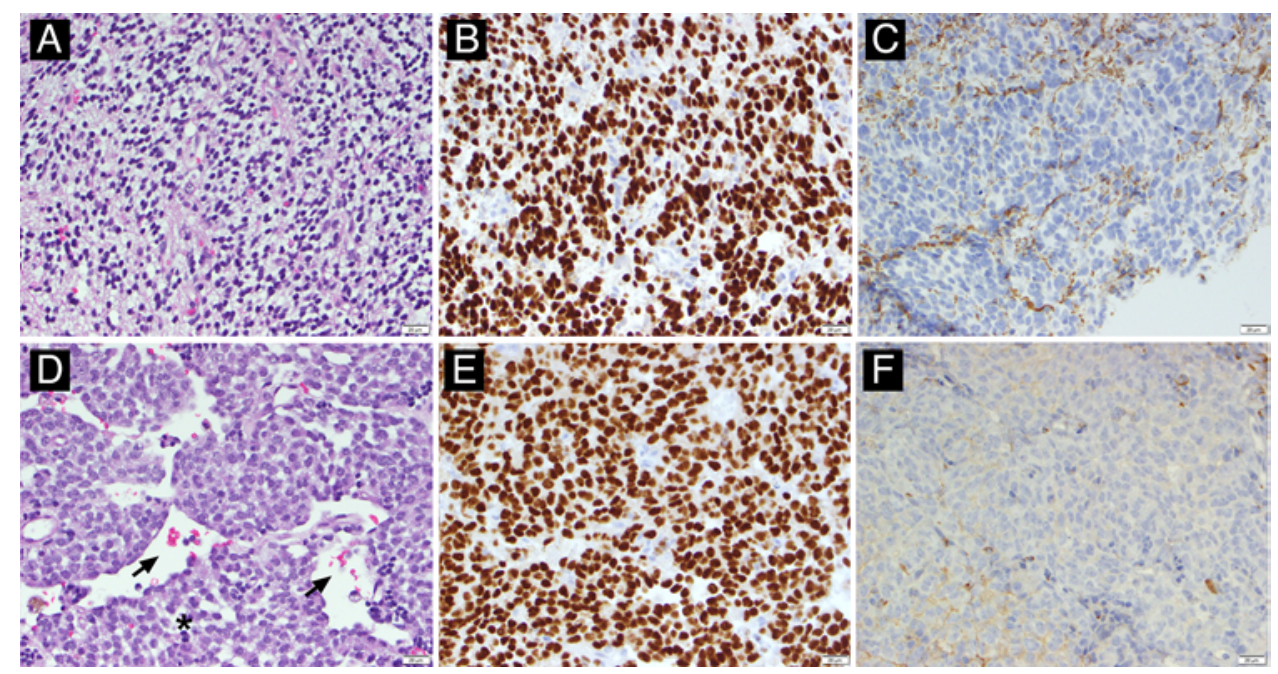

FIG. 1. Representative histopathology for low- and high-grade canine oligodendrogliomas. A: Low-grade oligodendroglioma (no. 017), H\&E stain. The neoplasm is densely cellular, composed of cells with a classic "fried egg" cytoplasmic retraction artifact and bland, monotonous nuclei with minimal atypia. This tumor had only rare mitotic activity, and no geographic necrosis or microvascular proliferation. B and C: Neoplastic cells have diffuse, strong nuclear immunolabeling for oligodendrocyte transcription factor 2 (Olig2; B) and lack immunolabeling for glial fibrillary acidic protein (GFAP; C). D: High-grade oligodendroglioma (no. 011), H\&E stain. The neoplasm is densely cellular, with round to ovoid cells aggregated in sheets admixed with minimal stroma, with numerous dilated blood vessels (arrows). In other areas (not pictured), this tumor had striking microvascular proliferation. Cells have variably defined, eosinophilic cytoplasm and plump ovoid or cleaved nuclei with clumped chromatin and 1-2 nucleoli. There are 1-2 mitotic figures (asterisk indicates telophase) per $\times 40$ field, and cells have moderate anisocytosis and anisokaryosis. $E$ and F: Neoplastic cells have diffuse, strong nuclear immunolabeling for Olig2 (E) and lack immunolabeling for GFAP (F). All images were taken at $\times 400$ magnification.

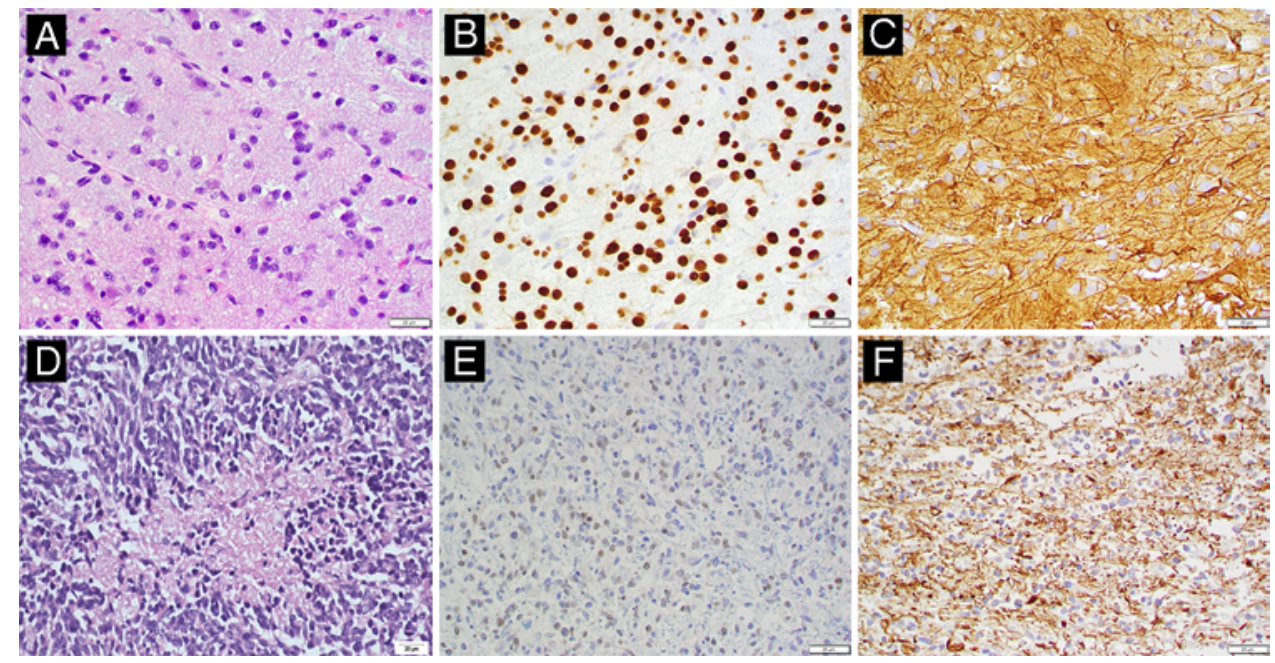

FIG. 2. Representative histopathology for low- and high-grade canine astrocytomas. A: Low-grade astrocytoma (no. 004). H\&E staining reveals a moderately cellular neoplasm consisting of loosely arranged streams and sheets of elongate cells supported by a scant fibrovascular stroma and faintly basophilic mucinous material. Neoplastic cells have mild pleomorphism and indistinct cytoplasmic borders, with a moderate amount of eosinophilic, finely fibrillar cytoplasm. Nuclei are round to elongate and have dense to finely stippled chromatin with 1-2 nucleoli and a low mitotic figure count. B and C: Neoplastic cells exhibit diffuse, strong nuclear immunolabeling for Olig2 (B) and strong cytoplasmic immunolabeling for GFAP (C). D: High-grade astrocytoma (no. 009, necropsy specimen). H\&E staining reveals a densely cellular neoplasm consisting of pleomorphic spindloid to polygonal cells that have indistinct cytoplasmic borders. Nuclei are irregularly round to elongate with coarsely stippled chromatin and variably distinct nucleoli. Extensive mitotic figures are present throughout the tumor (28/10 per high-power field) and there are multifocal areas of necrosis and hemorrhage throughout the tumor. E and F: Neoplastic cells exhibit multifocal, weak nuclear immunolabeling for Olig2 (E) and strong cytoplasmic immunolabeling for GFAP (F). 

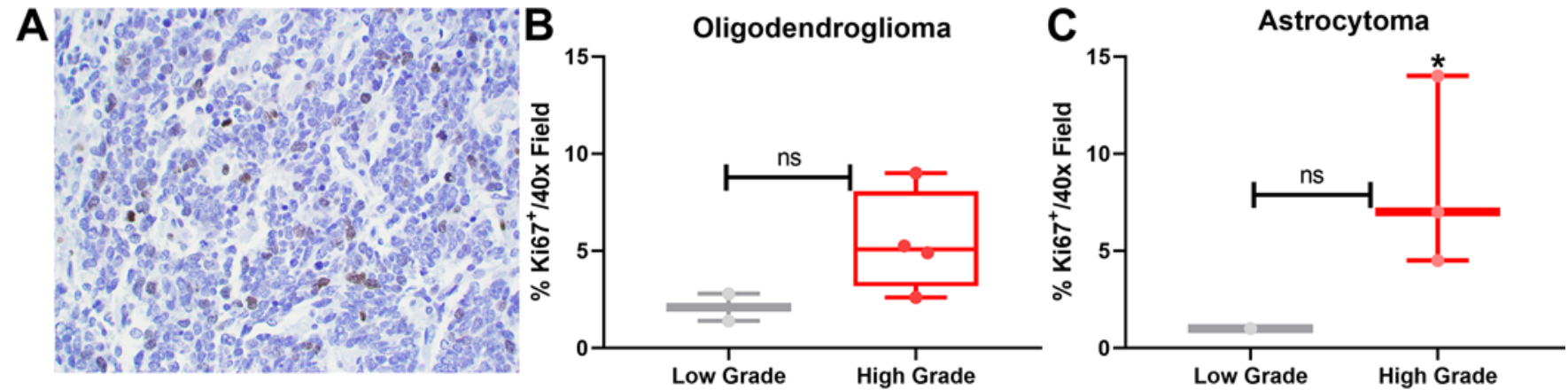

FIG. 3. High-grade oligodendrogliomas and astrocytomas have an increased percentage of Ki- $67^{+}$tumor cells. A: Representative image of Ki-67 expression in a field with $\times 400$ magnification. B and C: Ki-67 expression in tumors was assessed in noncontiguous images ( $n=10$ images/sample), and the average percentage of Ki-67 expression was calculated and graphed for both low- and high-grade oligodendrogliomas ( $B$; high grade, $n=4$; low grade, $n=2$ ) and astrocytomas $(C$; high grade, $n=3$; low grade, $n=2)$. The degree of Ki-67 expression trended in favor of high-grade tumors but did not reach statistical significance at this level of power $(p=$ 0.09 for oligodendrogliomas, $p=0.2$ for astrocytomas on unpaired t-testing). ns = not statistically significant; ${ }^{*}$ indicates glioblastoma.

hypertension and tachycardia immediately after the viral injection, which resolved with analgesic medication. The same dog developed frequent clusters of seizures within the first few weeks of surgery and underwent preemptive removal of the intracranial catheter and reservoir system. This did not immediately impact the dog's seizure frequency, but the seizures eventually resolved with escalation of medical therapy. Three dogs (nos. 009, 017, and 018) exhibited episodic pyrexia in the first few postoperative days, which resolved spontaneously in the first 2 cases. In the third case, fever resolved after removal of the dog's intravenous (IV) catheter. Thirteen dogs were treated with the goal maximum tolerated dose of $1 \times 10^{9} \mathrm{pfu}$ of M032 with no observed dose-limiting toxicities.

To date, 3 dogs have anomalously died within 30 days of treatment. One dog (no. 020) died suddenly 28 days after treatment, with no evidence of an inciting intracranial or systemic complication at necropsy, although there was a suggestion of leptomeningeal tumor spread. Another dog

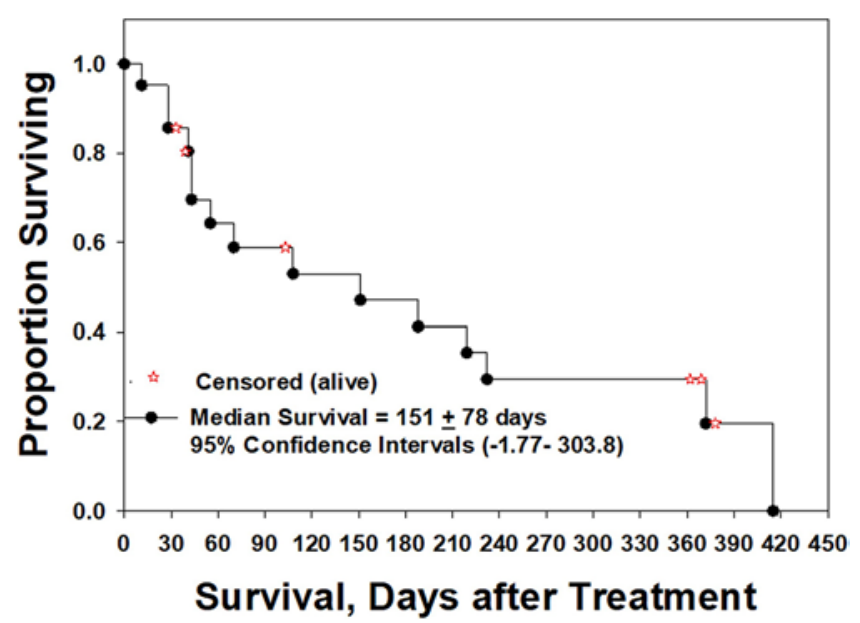

FIG. 4. Kaplan-Meier survival plot for 21 dogs treated with intratumoral infusion of M032 HSV. At the time of this report, 15 dogs had died and 6 were still alive (the 6 dogs that were still alive were censored in the plot, but their current survival times are denoted by the red stars on the plot). (no. 009) was euthanized 11 days after treatment due to cryptogenic clinical deterioration. At necropsy the dog was unexpectedly found to have a large invasive chemodectoma of the cardiac base and aorta with mediastinal lymphadenomegaly, as well as unilateral severe adrenocortical necrosis. The brain examination revealed expected postsurgical and neoplastic changes. The third dog (no. 017) was euthanized 28 days after surgery in light of failure to improve neurologically, in the setting of a tumor involving the right corona radiata and internal capsule with left hemiparesis prohibiting mobilization. Necropsy revealed no other complications. In all 3 cases, activated foamy macrophages were present in the tumor cavity.

At the time of this report, no dog had exhibited signs of central nervous system or systemic alphaherpesvirus infection. With the exception of 1 dog (no. 001) with a single positive result that was negative on repeat testing and thus believed to be spurious, none of the canines had evidence of HSV-1 on conjunctival or salivary polymerase chain reaction (PCR) throughout the course of surveillance. Human IL-12 has not been detected in the plasma of any dog tested to date, suggesting a lack of systemic M032 dissemination. Necropsy on 1 dog (no. 020) demonstrated lymphocytic cuffing around a few brainstem vessels but no frank vasculitis. Analyses of necropsy specimens for evidence of local M032 oncolytic activity are forthcoming.

As of this report, further histopathologic studies and indepth immunohistochemical analysis, fluorescence-activated cell sorting (FACS), genetic assays, and quantitative radiographic analyses are underway and will be reported as they become available.

\section{Discussion}

The canine model of glioma has significant potential in the study of the disease. There is a strong emphasis on regular primary care surveillance and preventative medicine in pet dogs, allowing for increased detection of central nervous system malignancies. ${ }^{17}$ Management options after discovery include euthanasia; palliation with antiepileptic drugs, corticosteroids, and pain medication; or treatment 
with biopsy, surgical resection, and/or alkylating agent chemotherapy with or without focused radiation. ${ }^{6}$ Due to the variety of care settings, availability of treatments, variability in documentation, euthanasia, tolerance level for neurological complications, and regular use of empirical noninvasive treatment without biopsy in some practices, it is difficult to appreciate the natural history of canine brain tumors and compile large databases with normative data on survival based on tumor grades and management strategy.

According to the current understanding, survival outcomes are generally poor in dogs with gliomas, similar to those in humans with high-grade gliomas. There are studies suggesting that palliation and surgical resection alone each carry a similar survival prognosis of just over 2 months, with the latter being associated with high complication rates. ${ }^{6,18-23}$ Studies of other therapies remain experimental, with methodological difficulties and mixed results. ${ }^{6,24-26}$ Akin to high-grade gliomas in humans, conventional therapies for canine gliomas have limited efficacy, and the study of combination therapies targeting unique characteristics of these tumors and the pathways by which they evade both endogenous and exogenous antitumoral mechanisms is warranted in both species.

Whereas the human M032 trial targets patients with multiply recurrent glioblastoma for which standard therapeutic options have been exhausted, the CANINE trial has mostly recruited pet dogs with newly diagnosed gliomas of varying histopathology and grade. We have taken advantage of the lack of standard-of-care options in dogs with gliomas to study the effects of surgery and oncolytic viral therapy in treatment-naïve tumors, a potential avenue for the development of primary therapies. Unlike the human M032 trial, which involves stereotactic placement of externalized intratumoral catheters that are removed after viral administration, the CANINE trial has employed a fully implanted catheter to allow the option for future redosing and sampling and to serve as a fiducial marker on subsequent imaging. This also reduces the risk of accidental displacement of the catheter by the dog. In both trials, viral administration is performed postoperatively via catheter to establish a more controlled volume, speed, and accuracy of delivery, with the patient awake to monitor for adverse reactions. Both trials follow similar dose escalation schemes and clinical, radiographic, and laboratory surveillance schedules.

The dominant tumor in our cohort has been oligodendroglioma. In dogs, oligodendrogliomas are currently thought to comprise up to $70 \%$ of all gliomas, with smaller incidences of astrocytomas (20\%) and undefined gliomas $(10 \%) .{ }^{6}$ High-grade oligodendrogliomas are more common than low-grade oligodendrogliomas in dogs, and glioblastomas are rare. ${ }^{27}$ It has been shown that canine oligodendrogliomas are more genetically similar to human glioblastomas than human oligodendrogliomas, particularly in terms of upregulated genes. ${ }^{28}$ Favorable IDH1 mutations and $1 \mathrm{p} / 19 \mathrm{q}$ codeletions are rare in canine tumors. ${ }^{28}$ Due to differences in arrangement of the dog and human genome, it may be that canine oligodendrogliomas possess sufficient genetic information to behave as aggressively as WHO grade IV glioblastomas in humans, as evidenced by similar patterns of resistance to antitumoral agents and systemic immune interference. ${ }^{29}$

Overall, survival in our cohort has been favorable and is clearly superior to that in published data on outcomes in palliated dogs with gliomas. ${ }^{22}$ A number of patients have survived well beyond what would be expected within the limits of comparison to historical controls. A few dogs, on the other hand, experienced poorer survival, although these appear to be outliers for reasons previously noted. In-depth tumoral and systemic assays will hopefully shed light on these differences. While the study is currently not sufficiently powered to perform conclusive univariate and multivariate analyses to determine predictors for increased survival, this is primarily a feasibility and tolerability study, and the current data are presented to illustrate that the therapy is safe and exhibits a definite trend toward prolonged survival in comparison with normative data. A prospective randomized trial with a control arm would be needed to validate these findings, although this may not be ethically feasible if results continue to demonstrate significantly prolonged survival with treatment.

It is very encouraging that none of the dogs enrolled in the trial to date have exhibited adverse effects attributable to the oncolytic virus and that no dose-limit toxicities have been encountered at the goal maximum tolerable dose of $1 \times 10^{9} \mathrm{pfu}$. Preclinical studies in mice $^{30}$ and nonhuman primates (Aotus nancymae) ${ }^{31}$ using the M032 murine IL-12-expressing HSV-1 counterpart, M002, previously demonstrated the safety of intratumoral oncolytic herpes simplex virus (oHSV) inoculation in animal models. All subjects enrolled have tolerated the intracranial infusion well, with no significant symptoms or clinical signs attributable to the treatment. Importantly, no dog developed clinical or radiographic evidence of meningitis, encephalitis, vasculitis, ependymitis, ventriculitis (or complicating hydrocephalus), or systemic alphaherpesvirus infection. For the patients that underwent necropsy, sequelae of alphaherpesvirus infection have not been detected in systemic tissues.

Beyond the safety and tolerability of M032 therapy, as data are collected, the evaluation of multiple secondary outcome measures is currently underway to provide crucial perspective to the promising survival trends. These include comprehensive volumetric radiographic analyses for quantification of the extent of tumor resection, treatment response determination, assessment for treatment-mediated pseudoprogression, and defining progression-free survival. Analysis of postmortem central nervous system tissues for evidence of intratumoral viral replication and oncolytic activity is also forthcoming. Serum immunological studies from before and after treatment will further shed light on systemic immune changes in response to the viral therapy. These data will serve as an important source of comparison with results of both the human M032 trial and the next stage of this CANINE trial.

Building on prior canine research, data on toxicity studies with non-nervous system cancers will inform the dosing of indoximod in the second stage of this trial, in which the addition of the checkpoint inhibitor will be studied with the intent of enhancing the oncolytic herpesvirus effect. Although the degree of IDO signaling has not been 
directly assayed in canine glioma, the pathway is known to drive the pathogenesis of non-central nervous system tumors in dogs. ${ }^{32-34}$ Indoximod is commercially available and has shown promising immunomodulatory effects in canine metastatic melanoma and sarcoma when used in combination therapies. ${ }^{35,36}$ Prior studies have demonstrated elevated numbers of CD4+ Foxp3+ regulatory T cells intratumorally and in the peripheral blood of dogs with gliomas, as well as an increased proportion of plasmacytoid dendritic cells. ${ }^{29,37}$ In humans, the IDO pathway has been shown to play an important role in plasmacytoid dendritic cell-induced Foxp3+ regulatory T-cell differentiation. ${ }^{38}$ Forthcoming immunohistochemical analyses of our tumor specimens will allow us to validate the importance of IDO expression in canine gliomas. As with prior work on systemic malignancies, evaluation of immunotherapeutics in pet dogs with gliomas so starkly resembling those of their human counterparts is a rational step in validating therapies that will eventually be tested in humans.

It is important to consider that dogs in this trial are not being unduly maintained for experimental purposes and continue to experience a good quality of life as pet dogs, as the trial is in compliance with the American Veterinary Medical Association Guidelines for the Euthanasia of Animals, with strict criteria for inclusion of animals based on the canine Karnofsky score. ${ }^{39,40}$ While this may limit assessment of maximum survival potential or introduce some degree of bias, the policy is in congruence with the true-to-life care of pet dogs that, like their human glioma counterparts, are treated as patients rather than subjects.

Ultimately, this comparative oncological endeavor is intended to enhance understanding of glioma pathophysiology and aid in the development of novel primary and secondary therapies for this complex disease. As we continue to learn more about how pet dogs with brain tumors respond to therapies available to humans, the pathophysiological similarities become increasingly salient. Expanding upon this understanding through the work of this trial will help further validate the utility of the pet dog as a large-animal model for brain tumor research. Early data have suggested great potential in this realm. Additionally, the simultaneously running trial of M032 in adult human patients with recurrent glioblastoma, ${ }^{13}$ the newly enrolling adult trial of the chimeric oHSV C134, ${ }^{41}$ the recently completed trial of the oHSV G207 in pediatric patients with progressive/recurrent supratentorial tumors, ${ }^{42}$ and the ongoing trial of G207 in refractory/recurrent pediatric cerebellar tumors ${ }^{43}$ at our institution provide unique opportunities to compare data and methodology. This distinctive collaboration will help inform the design of future human and canine studies, with the goal of improving outcomes in both species in a bitranslational fashion.

\section{Conclusions}

At the present time, it is clear that oncolytic viral therapy with M032 is safe in canine patients, with no doselimiting toxicities or adverse events attributable to the treatment identified. Preliminary data suggest that this treatment may prolong survival in pet dogs with gliomas. Forthcoming in-depth radiographic volumetrics, tumoral assays, and analysis of the immunological and genetic data from these dogs will allow better characterization of correlates for increased survival. The addition of systemic indoximod therapy during the second stage of this trial and comparison with data from the ongoing human M032 trial will provide additional avenues for data interpretation and application. Ultimately, the goal of these studies is to further corroborate the validity of the pet dog as a large-animal model for glial tumors and, through the One Health approach to medicine, enhance the understanding of therapeutic modalities that will improve outcomes in both people and pets.

\section{Acknowledgments}

This work was supported by USPHS, NIH, NCI grant U01 CA224151-01 (Cancer Moonshot Canine Immunotherapy Trials and Correlative Studies), and a pilot grant from the O'Neal Comprehensive Cancer Center (P30 CA13148-43). M032 was generated by the NCI RAID (5M01RR000032-420636) Program at SAIC Frederick for IND-directed safety and biodistribution studies, and for future clinical evaluation. Preliminary and ongoing investigations are supported by core facilities at The University of Alabama at Birmingham, including the Comparative Pathology Lab and Heflin Center for Genomic Sciences. The funders had no role in the design of the study; in the collection, analyses, or interpretation of data; in the writing of the manuscript; or in the decision to publish the results.

\section{References}

1. Nabors LB. Central nervous system: notable developments in the management of primary and recurrent gliomas. J Natl Compr Canc Netw. 2016;14(5)(suppl):681-684.

2. Jain KK. A critical overview of targeted therapies for glioblastoma. Front Oncol. 2018;8:419.

3. Shergalis A, Bankhead A III, Luesakul U, et al. Current challenges and opportunities in treating glioblastoma. Pharmacol Rev. 2018;70(3):412-445.

4. Wen PY, Weller M, Lee EQ, et al. Glioblastoma in adults: a Society for Neuro-Oncology (SNO) and European Society of Neuro-Oncology (EANO) consensus review on current management and future directions. Neuro Oncol. 2020;22(8): $1073-1113$.

5. Foreman PM, Friedman GK, Cassady KA, Markert JM. Oncolytic virotherapy for the treatment of malignant glioma. Neurotherapeutics. 2017;14(2):333-344.

6. Miller AD, Miller CR, Rossmeisl JH. Canine primary intracranial cancer: a clinicopathologic and comparative review of glioma, meningioma, and choroid plexus tumors. Front Oncol. 2019;9:1151.

7. Zinsstag J, Schelling E, Waltner-Toews D, Tanner M. From "one medicine" to "one health" and systemic approaches to health and well-being. Prev Vet Med.2011;101(3-4):148-156.

8. Evans BR, Leighton FA. A history of One Health. Rev Sci Tech. 2014;33(2):413-420.

9. Chambers MR, Bentley RT, Crossman DK, et al. The One Health Consortium: design of a phase I clinical trial to evaluate M032, a genetically engineered HSV-1 expressing IL-12, in combination with a checkpoint inhibitor in canine patients with sporadic high grade gliomas. Front Surg. 2020;7:59.

10. Roth JC, Cassady KA, Cody JJ, et al. Evaluation of the safety and biodistribution of M032, an attenuated herpes simplex virus type 1 expressing hIL-12, after intracerebral administration to Aotus nonhuman primates. Hum Gene Ther Clin Dev. 2014;25(1):16-27.

11. Pavlin D, Cemazar M, Sersa G, Tozon N. IL-12 based gene therapy in veterinary medicine. J Transl Med. 2012;10:234. 
12. Springer SL, Vite $\mathrm{CH}$, Polesky AC, et al. Infection and establishment of latency in the dog brain after direct inoculation of a nonpathogenic strain of herpes simplex virus-1. J Neurovirol. 2001;7(2):149-154.

13. Patel DM, Foreman PM, Nabors LB, et al. Design of a phase I clinical trial to evaluate M032, a genetically engineered HSV-1 expressing IL-12, in patients with recurrent/progressive glioblastoma multiforme, anaplastic astrocytoma, or gliosarcoma. Hum Gene Ther Clin Dev. 2016;27(2):69-78.

14. Zhai L, Lauing KL, Chang AL, et al. The role of IDO in brain tumor immunotherapy. J Neurooncol. 2015;123(3): 395-403.

15. Adams $\mathrm{S}$, Teo $\mathrm{C}, \mathrm{McD}$ onald $\mathrm{KL}$, et al. Involvement of the kynurenine pathway in human glioma pathophysiology. PLoS One. 2014:9(11):e112945.

16. Koehler JW, Miller AD, Miller CR, et al. A revised diagnostic classification of canine glioma: towards validation of the canine glioma patient as a naturally occurring preclinical model for human glioma. J Neuropathol Exp Neurol. 2018; 77(11):1039-1054.

17. Ostrander EA, Dreger DL, Evans JM. Canine cancer genomics: lessons for canine and human health. Annu Rev Anim Biosci. 2019;7:449-472.

18. Snyder JM, Shofer FS, Van Winkle TJ, Massicotte C. Canine intracranial primary neoplasia: 173 cases (1986-2003). J Vet Intern Med. 2006;20(3):669-675.

19. Foster ES, Carrillo JM, Patnaik AK. Clinical signs of tumors affecting the rostral cerebrum in 43 dogs. $J$ Vet Intern Med. 1988;2(2):71-74

20. Rossmeisl JH Jr, Jones JC, Zimmerman KL, Robertson JL. Survival time following hospital discharge in dogs with palliatively treated primary brain tumors. J Am Vet Med Assoc. 2013;242(2):193-198.

21. Heidner GL, Kornegay JN, Page RL, et al. Analysis of survival in a retrospective study of 86 dogs with brain tumors. $J$ Vet Intern Med. 1991;5(4):219-226.

22. Hu H, Barker A, Harcourt-Brown T, Jeffery N. Systematic review of brain tumor treatment in dogs. $J$ Vet Intern Med. 2015;29(6):1456-1463.

23. Suñol A, Mascort J, Font C, et al. Long-term follow-up of surgical resection alone for primary intracranial rostrotentorial tumors in dogs: 29 cases (2002-2013). Open Vet J. 2017; 7(4):375-383.

24. Moirano SJ, Dewey CW, Wright KZ, Cohen PW. Survival times in dogs with presumptive intracranial gliomas treated with oral lomustine: a comparative retrospective study (20082017). Vet Comp Oncol. 2018;16(4):459-466.

25. Dolera M, Malfassi L, Bianchi C, et al. Frameless stereotactic radiotherapy alone and combined with temozolomide for presumed canine gliomas. Vet Comp Oncol. 2018;16(1):90-101.

26. Van Meervenne S, Verhoeven PS, de Vos J, et al. Comparison between symptomatic treatment and lomustine supplementation in 71 dogs with intracranial, space-occupying lesions. Vet Comp Oncol. 2014;12(1):67-77.

27. Bentley RT, Ahmed AU, Yanke AB, et al. Dogs are man's best friend: in sickness and in health. Neuro Oncol. 2017; 19(3):312-322.

28. Mitchell D, Chintala S, Fetcko K, et al. Common molecular alterations in canine oligodendroglioma and human malignant gliomas and potential novel therapeutic targets. Front Oncol. 2019;9:780.

29. Filley A, Henriquez M, Bhowmik T, et al. Immunologic and gene expression profiles of spontaneous canine oligodendrogliomas. J Neurooncol. 2018;137(3):469-479.

30. Hellums EK, Markert JM, Parker JN, et al. Increased efficacy of an interleukin-12-secreting herpes simplex virus in a syngeneic intracranial murine glioma model. Neuro Oncol. 2005;7(3):213-224.

31. Markert JM, Cody JJ, Parker JN, et al. Preclinical evaluation of a genetically engineered herpes simplex virus expressing interleukin-12. J Virol. 2012;86(9):5304-5313.

32. Park JS, Withers SS, Modiano JF, et al. Canine cancer immunotherapy studies: linking mouse and human. J Immunother Cancer. 2016;4(1):97.

33. Prendergast GC, Smith $\mathrm{C}$, Thomas $\mathrm{S}$, et al. Indoleamine 2,3-dioxygenase pathways of pathogenic inflammation and immune escape in cancer. Cancer Immunol Immunother. 2014;63(7):721-735.

34. Porcellato I, Brachelente C, De Paolis L, et al. FoxP3 and IDO in canine melanocytic tumors. Vet Pathol. 2019;56(2): 189-199.

35. Monjazeb AM, Kent MS, Grossenbacher SK, et al. Blocking indolamine-2,3-dioxygenase rebound immune suppression boosts antitumor effects of radio-immunotherapy in murine models and spontaneous canine malignancies. Clin Cancer Res. 2016;22(17):4328-4340.

36. Watanabe T, Gaedicke S, Guffart E, et al. Adding indoximod to hypofractionated radiotherapy with anti-PD-1 checkpoint blockade enhances early NK and CD8 ${ }^{+} \mathrm{T}$-cell-dependent tumor activity. Clin Cancer Res. 2020;26(4):945-956.

37. Pi Castro D, José-López R, Fernández Flores F, et al. Expression of FOXP3 in canine gliomas: immunohistochemical study of tumor-infiltrating regulatory lymphocytes. J Neuropathol Exp Neurol. 2020;79(2):184-193.

38. Chen W, Liang X, Peterson AJ, et al. The indoleamine 2,3-dioxygenase pathway is essential for human plasmacytoid dendritic cell-induced adaptive T regulatory cell generation. $J$ Immunol. 2008;181(8):5396-5404.

39. Leary S. AVMA Guidelines for the Euthanasia of Animals: 2013 Edition. American Veterinary Medical Association; 2013. Accessed December 16, 2020. https://www.avma.org/ $\mathrm{KB} /$ Policies/Documents/euthanasia.pdf

40. Shores A. Development of a coma scale for dogs: prognostic value in craniocerebral trauma. In: Proceedings of the 6th Annual Veterinary Medical Forum. American College of Veterinary Internal Medicine; 1988:251-253.

41. Cassady KA, Bauer DF, Roth J, et al. Pre-clinical assessment of C134, a chimeric oncolytic herpes simplex Virus, in mice and non-human primates. Mol Ther Oncolytics. 2017;5:1-10.

42. Bernstock JD, Wright Z, Bag AK, et al. Stereotactic placement of intratumoral catheters for continuous infusion delivery of herpes simplex virus -1 G207 in pediatric malignant supratentorial brain tumors. World Neurosurg. 2019;122: e1592-e1598.

43. Bernstock JD, Bag AK, Fiveash J, et al. Design and rationale for first-in-human phase 1 immunovirotherapy clinical trial of oncolytic HSV G207 to treat malignant pediatric cerebellar brain tumors. Hum Gene Ther. 2020;31(19-20): $1132-1139$.

\section{Disclosures}

J.M.M. and G.Y.G. are founders of and own stock and stock options ( $<8 \%$ interest) in Aettis Inc., a biotech company that is developing other oHSVs that are not the subject of this current investigation. G.Y.G. currently serves as one of five unpaid members of the Board of Directors for Aettis Inc. J.M.M. and G.Y.G. are founders of and own stock and stock options $(<25 \%)$ in Treovir, LLC, which has licensed G207 HSV that is not the subject of the current investigation. G.Y.G. has served as a paid advisor to the Program Project (Brigham and Women's Hospital, Boston, MA) that seeks to find improved methods for the application of distinct oHSV to treat localized and metastatic cancers. This is generally, but not specifically, related to the subject matter of this investigation. J.M.M. also holds intellectual property in another oHSV not the subject of this current investigation that has been licensed by Mustang Biotech Inc., and reports being an equity owner in Catherex $(<8 \%)$, which underwent a structured 
buyout by Amgen; has ownership in Aettis Inc. and Treovir, LLC; and is a consultant for Imugene.

\section{Author Contributions}

Conception and design: Bentley, Crossman, Foote, Koehler, Markert, Shores, Sorjonen, Yanke, Gillespie, Chambers.

Acquisition of data: Bentley, Crossman, Koehler, Platt, Rissi,

Shores, Sorjonen, Yanke, Chambers. Analysis and interpretation of data: Omar, Foote, Koehler, Rissi, Gillespie, Chambers.

Drafting the article: Omar, Chambers. Critically revising the article: Omar, Bentley, Foote, Markert, Rissi, Shores, Gillespie, Chambers. Reviewed submitted version of manuscript: all authors. Approved the final version of the manuscript on behalf of all authors: Omar. Statistical analysis: Omar, Gillespie. Administrative/technical/material support: Crossman, Foote, Koehler, Markert, Platt, Rissi, Shores, Sorjonen, Yanke, Gillespie, Chambers. Study supervision: Markert, Platt, Gillespie, Chambers.

\section{Correspondence}

Nidal B. Omar: The University of Alabama at Birmingham, AL. nidalomar@uabmc.edu. 